\title{
Platelet Indices in Male and Female German Shepherd Dogs in the Sudan
}

\author{
*Nidaa.A.Mohammed ${ }^{1}$; Shamseldein.H.Ahmed ${ }^{2}$; Shadia.A.Omer ${ }^{2}$ and \\ Gusai.H.Abdel Sammad ${ }^{3}$ \\ 1Department of Animal Physiology College of veterinary Medicine -University of Bahri -Khartoum -Sudan \\ 2Department of Basic Science-College of Veterinary Medicine - Sudan University of Science and Technology, \\ Khartoum -Sudan \\ 3Department of Microbiology College of veterinary Medicine- University of Bahri-Khartoum -Sudan \\ *Corresponding Author Nidaa.A.Mohammed*
}

\begin{abstract}
The objectives of this study are to find reference values for German shepherd dog reared in Sudan, evaluate the effects of sex on platelet parameters, correlations between platelets indices. Thirty three healthy dogs aged between 2 to 4 years of the breed German shepherd in the Sudan were categorized into two sex groups (14males, 19 females) were used in this study. Five $\mathrm{ml}$ Blood samples were taken from cephalic vein and analysis was performed using the Sysmex KX2 hematology analyzer. The following parameters were evaluated: platelet count $(P L T)$, mean platelet volume (MPV), platelet crit (PCT), and platelet distribution width (PDW), along with parallel red blood cell parameters. The overall mean values of platelet parameter were: PLT $183.52 \pm 59.97\left(\times 10^{9} / \mathrm{L}\right), \quad M P V \quad 9.19 \pm 0.96 f l, \quad P C T \quad 0.13 \pm 0.09 \%$ and PDW15.61 $\pm 0.90 \%$. Significant sex differences were observed for platelet count and red cell distribution width $(P \leq 0.05)$ between male and female. Significant $(P \leq 0.01)$ correlation was found between PLT and PCT in female and the over all, No significant correlations between PLT and MPV, PDW in the two sexes, moreover, significant correlations $(P \leq 0.01)$ were observed between $P D W$ and $R B C, M C V$, and $R D W$ in the over all. However, no significant correlations were detected between RBC and PLT, PCT, and PCV in all dogs. Effect of sex should be considered in clinical interpretation of dog platelet variables. Determined reference values may be useful information for an increasing clinical use
\end{abstract}

Keywords: Platelet variables-Sex-Platelet count-German Shepherd dogs

\section{Introduction}

Platelets are a part of the blood that helps the blood clot Guyton and Hall( 2006).Platelets volume (MPV) and platelets crit (PCT) are indices used in evaluating immune mediated thrombocytopenia (IMT) in dogs and humans with congenital macrothrombocytopenia (David et al,2008). The higher MPV is a larger platelets size and the platelets distribution width ( PDW) reflects the variability in the platelets size, (Amin, et al (2004). PLT and PCT values may be used as valuable parameters for diagnosis and probably for monitorization and prognosis in infected dogs with Ehrlichiosis and/or Anaplasmosis.( Funda and Kerem,2014). Previous data proved that platelet count may be a reliable screening test for dog granulocytic ehrlichiosis (Bexfield, et al2005, Mazepa,et al 2010), and dog monocytic ehrlichiosis (Bulla,et al ,2004). The effect of breed and age should be considered in clinical interpretation of dog platelet variables (Lysann and Reinhard, 2016).

The aims of this study are to assess the effects of sex on platelet and red blood cells indices, correlations between platelets indices as well as to find reference values for German shepherd dog in Sudan.

\section{Materials and methods}

Study design and Animals: The present study was enrolled among 33 dogs (14male/19 female; aged from 2 to 4 years) belonging to the Police Directorate for Dogs at Khartoum State during the year 2014. The dogs belong to German Shepherd breeds. They were apparently healthy on clinical examination. All the females were non pregnant and non lactating. The dogs were housed in kennels individually and were fed chicken soup with noodles,(imported dog food not available at that time, the Besterly Senior-the Netherland).

Informed written consent was obtained from the director of the police directorate for dogs prior to enrolment of the dogs participated in study.

Haematological examinations. five ml blood samples were withdrawn from cephalic vein into anti coagulated (EDTA- k3) tubes. Complete blood counts were performed on referral within - each tube was gently inverted 3- 
4 times to insure mixing of sample and immediately transported to the laboratory using an automated hematology analyzer Sysmex KX2 IN. The samples were analyzed for PLT, PCT, MPV and PDW, as well as RBC, packed cell volume (PCV), mean cell hemoglobin ( $\mathrm{MCH})$, mean cell hemoglobin concentration (MCHC), hemoglobin concentration $(\mathrm{Hb})$ and red cell distribution width (RDW). Hematology analyzer with special reference to thrombocyte indices, mean plateled volume (MPV), and plateletcrit (PCT).

\section{Statistic analysis:}

The data were presented as means \pm standard deviation. The differences for mean values among groups were detected by student's $t$ test as described by Gomez and Gomez, (1984). Overall means and range were calculated. The nonparametric test was used to determine the normality and Spearman correlations were used to determine correlations among platelets indices and between the platelets and parallel red cell parameters.

\section{Results}

Hematological analysis. Table (1) shows hematological variables obtained (means, standard deviation and the total ranges for platelets and RBC parameters). Female showed significant $(p \leq 0.02)$ differences in mean of platelets count and RDW than male, whereas, male showed higher values of red cell indices but not significant.

Table 1. Platelets indices and Red Cells parameters in male and female German Shepherd Dogs in Sudan

\begin{tabular}{|c|c|c|c|}
\hline Parameter & Male & Female & Overall \\
\hline \multicolumn{4}{|c|}{ Platelets indices } \\
\hline $\operatorname{PLT}\left(\times 10^{9} / \mathrm{L}\right)$ & $170.50 \pm 43.78^{\mathrm{b}}$ & $193.11 \pm 56.81^{a^{*}}$ & $183.52 \pm 59.97$ \\
\hline PCT $(\%)$ & $0.11 \pm 0.031$ & $0.14 \pm 0.03$ & $0.13 \pm 0.038$ \\
\hline $\mathrm{MPV}(f \mathrm{~L})$ & $9.51 \pm 0.71$ & $8.96 \pm 1.06$ & $9.19 \pm 0.96$ \\
\hline PDW (\%) & $15.49 \pm 0.91$ & $15.69 \pm 0.91$ & $15.61 \pm 0.90$ \\
\hline \multicolumn{4}{|c|}{ Red cells indices } \\
\hline $\operatorname{RBC}\left(\times 10^{12}\right)$ & $6.60 \pm 0.81$ & $6.35 \pm 0.74$ & $6.46 \pm 0.77$ \\
\hline PCV (\%) & $46.57 \pm 4.93$ & $44.73 \pm 5.16$ & $45.5 \pm 5.07$ \\
\hline $\mathrm{MCV}(f \mathrm{~L})$ & $70.79 \pm 2.49$ & $70.56 \pm 4.47$ & $70.66 \pm 3.71$ \\
\hline $\mathrm{MCH}(\mathrm{pg})$ & $27.65 \pm 1.58$ & $27.53 \pm 2.15$ & $27.58 \pm 1.89$ \\
\hline $\mathrm{MCHC}(\%)$ & $39.15 \pm 1.96$ & $39.19 \pm 2.19$ & $39.17 \pm 2.07$ \\
\hline $\mathrm{Hb}(\mathrm{gm} / \mathrm{dl})$ & $18.25 \pm 2.26$ & $17.09 \pm 3.71$ & $17.58 \pm 3.19$ \\
\hline RDW (\%) & $14.14 \pm 0.53^{\mathrm{b}}$ & $14.68 \pm 1.95^{\mathrm{a}^{*}}$ & $14.45 \pm 1.51$ \\
\hline
\end{tabular}

$* \mathrm{P} \leq 0.05$

Correlation analysis for relevant hematological variables: In the present study correlation among those three thrombocyte indices(PLT $\left(\times 10^{9} / \mathrm{L}\right), \operatorname{PCT}(\%), \operatorname{MPV}(f \mathrm{~L})$ and $\operatorname{PDW}(\%)$ were investigated for all groups. Significant correlation $(\mathrm{P} \leq 0.01)$ was found between PLTand PCT in females and the overall dogs, while male represented low significant $(\mathrm{P} \leq 0.05)$ correlation.No significant correlation between PLT and MPV, PDW in all dogs. The correlation between platelet parameters and parallel red blood cell(RBC) parameters packed cell volume (PCV), mean corpuscular volume(MCV) and red cell distribution width (RDW), showed.No significant correlation was found between RBC and PLT, PCT, and PCV in all dogs, (Table3). However a highly significant correlation $(\mathrm{P} \leq 0.01)$ was found between $\mathrm{PDW}$ and $\mathrm{RBC}, \mathrm{MCV}$, and RDW in all dogs. Low significant correlations $(\mathrm{p} \leq 0.05)$ was found between MPV and RDW in the overall dogs and female.PDW was highly correlated $(\mathrm{P} \leq 0.01)$ with $\mathrm{MCV}$ and $\mathrm{RDW}$ in female. Low significant correlation $(\mathrm{P} \leq 0.05)$ between $\mathrm{PDW}$ and MCV was found in male, further more female was showed a highly significant correlation $(\mathrm{P} \leq 0.01)$ between PDW, MCV, and RDW. Low significant correlation ( $\mathrm{P} \leq 0.05)$ between PLT and MCV in male. The female performed low significant correlation between PWD and RBC.

Table 2: Correlation among Platelets Indices in German Shepherd Dogs in Sudan

\begin{tabular}{|l|l|l|l|l|}
\hline Parameter & PLT $\left(\times 10^{9} / \mathrm{L}\right)$ & PCT $(\%)$ & MPV $(f \mathrm{~L})$ & Over all \\
\hline \multicolumn{5}{|l|}{$(\%)$} \\
\hline PLT $\left(\times 10^{9} / \mathrm{L}\right)$ & 1 & $0.880^{* * *}$ & 0.046 & -0.336 \\
\hline PCT $(\%)$ & $0.880^{* *}$ & 1 & 0.098 & -0.087 \\
\hline MPV $(f \mathrm{~L})$ & 0.046 & 0.098 & 1 & 0.190 \\
\hline PDW $(\%)$ & -0.336 & -0.087 & 0.19 & 1 \\
\hline \multicolumn{5}{|c|}{ Males } \\
\hline PLT $\left(\times 10^{\%} / \mathrm{L}\right)$ & 1 & $0.634^{*}$ & 0.454 & -0.465 \\
\hline PCT $(\%)$ & $0.634^{*}$ & 1 & 0.217 & 0.283 \\
\hline MPV $(f \mathrm{~L})$ & 0.454 & 0.217 & 1 & -0.024 \\
\hline PDW $(\%)$ & -0.465 & 0.283 & -0.024 & 1 \\
\hline \multicolumn{5}{|c|}{ Females } \\
\hline PLT $\left(\times 10^{9} / \mathrm{L}\right)$ & 1 & $0.960^{* *}$ & 0.001 & -0.332 \\
\hline
\end{tabular}


Platelet Indices in Male and Female German Shepherd Dogs in the Sudan

\begin{tabular}{|l|l|l|l|l|}
\hline PCT $(\%)$ & $0.960^{* * *}$ & 1 & 0.152 & -0.320 \\
\hline MPV $(f \mathrm{~L})$ & 0.001 & 0.152 & 1 & 0.364 \\
\hline PDW $(\%)$ & -0.332 & -0.320 & 0.364 & 1 \\
\hline
\end{tabular}

$* \mathrm{P} \leq 0.05 * * \mathrm{P} \leq 0.01$ - reverse correlate

Table (3) Correlation between Platelet indices and Parallel Red Blood Cell Parameters in German Shepherd Dogs in Sudan

\begin{tabular}{|c|c|c|c|c|}
\hline Parameter & $\operatorname{PLT}\left(\times 10^{9} / \mathrm{L}\right)$ & PCT (\%) & $\mathrm{MPV}(f \mathrm{~L})$ & PDW\% \\
\hline \multicolumn{5}{|c|}{ Over all } \\
\hline PCV (\%) & 0.042 & -0.035 & 0.163 & -0.217 \\
\hline RDW (\%) & 0.012 & -0.61 & $-0.434^{*}$ & $-0.544^{* *}$ \\
\hline \multicolumn{5}{|c|}{ Male } \\
\hline $\mathrm{RBC}\left(\times 10^{12} / \mathrm{L}\right)$ & 0.263 & 0.023 & 0.048 & -0.403 \\
\hline $\operatorname{MCV}(f \mathrm{~L})$ & $-0.553^{*}$ & -0.262 & 0.038 & $0.564^{*}$ \\
\hline RDW (\%) & -0.124 & -0.425 & 0.060 & -0.476 \\
\hline \multicolumn{5}{|c|}{ Female } \\
\hline $\mathrm{RBC}\left(\times 10^{12} / \mathrm{L}\right)$ & 0.191 & 0.160 & -0.013 & $-0.512^{*}$ \\
\hline PCV (\%) & 0.070 & 0.035 & 0.141 & -0.153 \\
\hline $\operatorname{MCV}(f \mathrm{~L})$ & -0.241 & -0.241 & 0.315 & $0.694^{* *}$ \\
\hline
\end{tabular}

$* \mathrm{P} \leq 0.05$

$* * \mathrm{P} \leq 0.01$

- reverse correlate

\section{Discussion}

There is a scarcity in publication regarding the correlation between platelet indices and their parallel red cell indices in Shepherd dogs in Sudan. In the current study a higher platelet counts and slight rise in PCT were found in the German Shepherd female's dog in Sudan than the male, this significant difference between male and female for the previous parameters is on line with what reported in Humans by Giacomoini et al(,2001), Lawrir et al,(2009). The difference between the sex may be attributed to hormonal profile (Bain 1985).

The present study revealed a high significant correlation between PLT count and PCT in the overall dogs and female and low significant correlation between the previous parameters in male. Hussein et al (2010) found similar result in camels except of that male showed highly significant correlation between the two parameters. On the other hand there was no significant correlation between PLT and MPV this was agreed with Hussein et al(2010) in camels. No significant difference between male and female in PDW and MPV, this was on line with Awad Elkareem et al(2015),Botma et al(2012),Punnet etal(2014) in Humans, and contrasted with the findings of Hussein et al (2010) in camels.In the current study there was no significant correlation between PCT and MCV or between MPV and MCV ,this be through with the findings of Wiwanitkit(2004) in Humans as well as Hussein et al (2010) in camels confirming the view that the sizes of RBC and blood platelets are independent of each other (Wiwanitikit 2004).However, in concur with these authors, a highly significant inverse correlation was found between PDW and RDW in all dogs. More over a highly reverse correlation was found between PDW and RBC in the over all, while a highly proportional correlation was found between PDW and MCV ,this contrast with the findings of Hussein et al (2010) in camels.

The red blood cell parameters within the normal range for dogs and various species of farm animals( Feldman et al2000), as well as no significant differences were found between male and female for red blood cells count $\mathrm{PCV}, \mathrm{MCV}, \mathrm{MCH}, \mathrm{MCHC}$ and hemoglobin concentration, this findings were agreed with the findings of Gracnier et al (2007), Rovira (2007), Shiela et al(2007) and Lund et al(2000) in dogs. On the contrary Aroch et al(2005) obtained higher RBC count,Hb,PCV,MCHC values in free ranging males golden jackals than the females. That likely as the result of climate variation, species, animal habitat, method of sampling and the device used in the examination of the samples. 


\section{References}

[1]. Amin M.A; Amin, A.P and Kulkarnite, H.R (2004).Platelet distribution width(PDW) is increased in vaso-oclusive crisis in sickle cell disease. Anna Hematology; 83(6):331-335.

[2]. Arcoh I.; Shipgel, N.Y.; Avidar, Y.; Yakobson, B King, R, and Shamir. M. (2005). Hematological and biochemical measurements in healthy adult, free- ranging golden jackals (Canis aureus syriacus) held in captivity. Vet. Rec.10:317-321.

[3]. Awad-Elkareem,A ;Israa, I;Razaz, Y;Eman,A ;Reem, M;Sara ,M;Haifa,A and Adam.,A.(2015).Reference value of Platelets count and indices in Sudanese using Sysmex KX-21.Inter. j of health sci. 3(2): 120-125.

[4]. Bain .B.J(1985).Platelet count and Platelet size in males and females.Scand J Hema;35:77-79.

[5]. Bexfield, N.H; Villiers, E.J; Herrtage, M.E.(2005) . Immune-mediated haemolytic anaemia and thrombocytopenia associated with Anaplasma phagocytophilum in a dog. J Small Anim Pract; 46:543-548.

[6]. Botma. J; Mogongoa ,L.F; Jaftha,A.D;Janse van Rensburg W (2012).Reference ranges for Platelet indices using Sysmex XE2100 blood analyser.Med Tech S A fr; 26(2):17-12.

[7]. Bulla ,C; Takahira ,R.K; Araújo, J.P; Trinca, A.L; Lopes, S.R; Wiedmeyer, C.E. (2004). The relationship between the degree of thrombocytopenia and infection with Ehrlichia canis in an endemic area. Vet Res; 35(1):141-146.

[8]. David, C.Lewis and Kenneth ,M.Meyers. (2008).J. Vet.Inter.Medi 101( 4 ) version of research on line.

[9]. Feldman,B.F;Zinkl, J.G;Jain, N.C. (2000).Schalm's Vet Hema,5 ${ }^{\text {th }}$ ed.Wiley Blackwell,N.Y.USA. 529-536

[10]. Funda .Özata, and Kerem .Ural.(2014). Thrombocyte indices in dogs infected with Ehrlichia canis and Anaplasma phagocytophilum. Revista MVZ Cordoba ,.19:3 Córdoba .

[11]. Giacomoini. A; Legovivi .P; and Gessoni.,G.(2001). Platelet count and parameters determined by the Bayer ADVIA TM 120 in reference subjects and patients.Clin Lab Heama; 23:181-186.

[12]. Gomez, K.A and Gomez, A.A (1984).Statistical procedure for Agricultural research, 2nd ed.Wily and Sons, Inc.

[13]. Gracner. D.; Bedrica. L; Labura. C; Maticic. D; Gracner. G.G. and Samardzija. M. (2007). Blood Groups and Hematology. In: Istrian Pointers. Veterinararski Arhiv, 77:95-102.

[14]. Guyton. A.C; Hall .J.E. (2006). Textbook Of Medical physiology. $11^{\text {th }}$ ed:Elsevier Saunders.

[15]. Hussein. M ; Aljumaah. R; Alhaidary. A; Alshaikh. M; Mohammed. O; Omer. S; Gar-Elnabi. Aand Macasero. W. (2010).Platelets indices of the dromedary camel(camelus dromedaries).Vet.Archi 80 (3):375-382.

[16]. Lawrie. D;Coetzee. L.M;Becker. P;Mahlangu. J; Stevens,.W and Glencross. D.K. (2009).Local reference ranges for full blood count and CD4 lymphocyte count testing.S Afr Med J,99:243-248.

[17]. Lund. C; Kuhl.S.; Mischke. R and Gunzel-Apel. A.R. (2000). Reference values of the red blood profile in Beagles, German shepherd and Golden retriever puppies. Berl Munch Tierarztl Wochenschr, 113: 447-453.

[18]. Lysann .S. and Reinhard .M. (2016). Platelet variables in healthy dogs: reference intervals and influence of age, breed and sex.Comparative Clinical, 25 (6): 1097-1106.

[19]. Mazepa ,A.W; Kidd, L.B;Young ,K.M; Trepanier, L.A. (2010). Clinical presentation of 26 Anaplasma phagocytophilum seropositive dogs residing in an endemic area. J Am Anim Hosp Assoc; 46(6):405-412.

[20]. Punnet. Sachdeva;Gagandeep. Kaur;Sabita. Basu and Anita. Tahlan (2014). Assessment of factors affecting the platelet yield using continuous flow cell separator.Inter. J .of Biomed. Resch . 0976-9633(on line).

[21]. Rovira. S ; Munoz .A and Benito. M. (2007). Hematologic and biochemical changes during canine agility competitions. Vet Clin Pathol. 36: 30-35.

[22]. Shiela, R.E; Brennan, S.F; O'Rourke, L.G; Mc Cullough. M. and Mooney, C.T. (2007). Hematologic values in young pre training healthy Greyhounds, Vet. Clin. Pathol. 36: 274-277.

[23]. Wiwanitkit ,V.(2004 ). Plateletcrit, mean platelet volume, platelet distribution width: its expected values and correlation with parallel red blood cell parameters. Clin Appl Thromb Hemost. 10(2):175-178.

Nidaa.A.Mohammed. "Platelet Indices in Male and Female German Shepherd Dogs in the Sudan." IOSR Journal of Agriculture and Veterinary Science (IOSR-JAVS) 10.7 (2017): 60-63. 